\title{
Factors influencing the exit knowledge of patients for dispensed drugs at outpatient pharmacy of Hiwot Fana Specialized University Hospital, Eastern Ethiopia
}

\author{
This article was published in the following Dove Press journal: \\ Patient Preference and Adherence \\ 8 February 2017 \\ Number of times this article has been viewed
}

\author{
Nigatu Hirko' \\ Dumessa Edessa ${ }^{2}$ \\ 'Department of Pharmacy, Bisidimo \\ Hospital, East Hararghe Zone, \\ Oromia, Ethiopia; ${ }^{2}$ Department of \\ Pharmacology and Clinical Pharmacy, \\ School of Pharmacy, College of Health \\ and Medical Sciences, Haramaya \\ University, Harar, Ethiopia
}

\begin{abstract}
Background: A satisfactory counseling process between the patient and pharmacist is critical for rational use of dispensed drug(s) and is highly influenced by many factors including the experience of pharmacist in dispensing process. To improve patients' knowledge of dispensed drugs, it is necessary to understand the factors that optimize a pharmacist interaction with a patient in each activity of the dispensing process. Therefore, the aim of this study was to identify the pharmacist and patient factors that influence knowledge of dispensed drugs by ambulatory patients at Hiwot Fana Specialized University Hospital, Harar, Ethiopia.
\end{abstract}

Materials and methods: A cross-sectional study was conducted on 422 respondents. Data were collected by interviews using a structured questionnaire that measures "exit knowledge" of the ambulatory patients for dispensed drugs. The collected data were analyzed using SPSS Version 20.0. Potential covariates were identified using $\chi^{2}$ test, and logistic regression analyses were undertaken to adjust for the covariates.

Results: Our findings showed significant proportions of the patients did not recall the name of their dispensed medication (53.6\%), major side effects $(66.4 \%)$, and what to do in case of missed doses (65.4\%). Patients' knowledge of dispensed drugs was significantly associated with their educational level (adjusted odds ratio [AOR]: 1.97; 95\% confidence interval [CI]: 1.01-3.84 [primary], AOR: 2.04; 95\% CI: 1.04-4.04 [secondary], and AOR: 2.71; 95\% CI: 1.35-5.46 [tertiary]); clear instruction from the pharmacist (AOR: 3.36; 95\% CI: 1.16-9.72); and the politeness of the pharmacist (AOR: 2.02; 95\% CI: 1.04-4.04).

Conclusion: We found that the majority of patients poorly understood the name of the dispensed medication, side effects, and what to do in case of missed doses. In addition, the formal educational level of the patient, clear instruction from the pharmacist, and the politeness of pharmacist were the factors significantly associated with improved exit knowledge of patients for dispensed drugs. Therefore, increased communication skills training for pharmacists would optimize patient-pharmacist interaction, which in turn would likely improve exit knowledge of ambulatory patients for dispensed drugs.

Keywords: counseling quality, patient knowledge of dispensed drugs, factors associated

\section{Introduction}

Drug use is effective when patients receive the appropriate $\operatorname{drug}(\mathrm{s})$ in $\operatorname{dose}(\mathrm{s})$ correct to their own individual requirements, for an optimum period of time, and at the lowest cost both to them and the community. ${ }^{1}$ A multidisciplinary collaboration is needed to develop, implement, and evaluate interventions that promote more rational 
use of $\operatorname{drug}(s) .^{2}$ To this effect, the professional skills and experiences of pharmacists in dispensing processes greatly influence how medicines are used by ambulatory patients. ${ }^{1,3}$ Similarly, the educational level and motivation of the patient are also critical factors in this regard.

The communication ability of pharmacists is one of the crucial professional skills needed for dispensing process, and this is highly important for satisfactory counseling that motivates patients toward rational drug use. ${ }^{4}$ In line with this, for instance, the role of pharmacist counseling in preventing adverse drug events, ${ }^{5}$ and expanded roles in optimizing service utilization, decreasing unnecessary costs, and supporting physicians' prescribing practices to produce the intended effects are also evidenced. ${ }^{6}$ For successful accomplishment of such roles, the World Health Organization (WHO) requires the dispenser to be knowledgeable in the indications of medicines, their side effects, contraindications, and dosages for human use so that accurate information can be provided to patients, thereby improving their understanding of and adherence to treatments. ${ }^{7}$ Therefore, the qualification level of the dispenser could influence knowledge score of patients in regard to the drugs dispensed. ${ }^{8}$

Moreover, adequate consultation time given for patients, both by physicians and the dispensing pharmacists, is critical for proper understanding of why and how medicines are to be taken, for what purpose and for how long they are to be taken. ${ }^{7}$ In addition to the dispenser's or prescriber's role, the educational level and prescription experience of patients can affect their understanding about the drugs dispensed. ${ }^{9}$ The quality of interaction between pharmacist and patient is also found to affect patients' knowledge about dispensed drugs and their satisfaction with the service provided by the pharmacist. ${ }^{10}$ To make sure that patients understand the dosage regimen correctly and thereby increase their compliance with the correct regimen, average dispensing (counseling) time is critical. ${ }^{11}$ Accordingly, there is a need to improve patients' knowledge of dispensed drugs ${ }^{12}$ by addressing pharmacists' and patients' factors across nations in different geographic locations.

Therefore, the factors associated with improving the knowledge of patients for dispensed drugs need to be exhaustively identified in various cohorts of nations. In Ethiopia, studies that correlate factors associated with knowledge of patients in regard to dispensed drugs are limited. Therefore, this study tried to identify pharmacists' and patients' factors that influence "exit knowledge" of ambulatory patients for dispensed drugs at Hiwot Fana Specialized University Hospital (HFSUH), Harar town, Eastern Ethiopia.

\section{Materials and methods Study site and design}

The study was conducted at the outpatient pharmacy of HFSUH in Harari Region, Harar town, Eastern Ethiopia, from February to June, 2016. A cross-sectional study design was employed to assess the exit knowledge of dispensed drugs by ambulatory patients at this pharmacy. The study was designed and powered to evaluate the key study outcome (knowledge of dispensed drugs by ambulatory patients) among 422 patients.

\section{Study variables}

Age, sex, level of education, and other sociodemographic and patient-pharmacist interaction characteristics were the independent variables considered. The exit knowledge status of ambulatory patients about their dispensed drugs was the outcome variable assessed by this study. A patient is considered knowledgeable if he/she correctly answers at least eight of the twelve questions that were meant to assess the patients' knowledge of dispensed drugs (Table 1).

\section{Study participants}

The source population for this study was all the patients who came to outpatient pharmacy of the HFSUH. All patients who came to the outpatient pharmacy during February to June 2016 were considered the study population for the study. Patients coming to the outpatient pharmacy and willing to be interviewed during the data collection period were considered for the study; while all severely sick patients and patients who received greater than three medications from the outpatient pharmacy were excluded since information recall and retention abilities of such individuals was thought to be affected by the disease condition and the number of medications dispensed to them, respectively. Since there was adequate number of patients who were coming for pharmaceutical services during the data collection period, a random sampling method was used to select the study participants. The sample size of the study participants was calculated by the use of single proportion formula. For the sample size calculation, $\alpha$ was taken as $=0.05$ (two-tailed), confidence level $=95 \%$, and proportion of exit knowledge for dispensed drugs at outpatient pharmacy $=50 \%$. Accordingly, 384 subjects were determined as a minimum sample size; and after adding $10 \%$ of the calculated sample size for possible noncontingency, the final sample size was determined to be 422 patients.

\section{Data collection process}

Data were collected by interviewing patients on exit from the outpatient pharmacy by using a structured interview 
Table I Exit knowledge status of patients interviewed for dispensed medications at outpatient pharmacy of HFSUH, Harar, June 2016

\begin{tabular}{|c|c|c|}
\hline Knowledge status & Frequency & $\%$ \\
\hline \multicolumn{3}{|c|}{ Patient knows medication's name } \\
\hline No & 226 & 53.6 \\
\hline Yes & 196 & 46.4 \\
\hline \multicolumn{3}{|c|}{ Patient knows medication's indication } \\
\hline No & 149 & 35.3 \\
\hline Yes & 273 & 64.7 \\
\hline \multicolumn{3}{|c|}{ Patient knows medication's route of administration } \\
\hline No & 71 & 16.8 \\
\hline Yes & 351 & 83.2 \\
\hline \multicolumn{3}{|c|}{ Patient knows duration of therapy } \\
\hline No & 186 & 44.1 \\
\hline Yes & 236 & 55.9 \\
\hline \multicolumn{3}{|c|}{ Patient knows medication's frequency } \\
\hline No & 52 & 12.3 \\
\hline Yes & 370 & 87.7 \\
\hline \multicolumn{3}{|l|}{ Patient knows drug interaction } \\
\hline No & 176 & 41.7 \\
\hline Yes & 246 & 58.3 \\
\hline \multicolumn{3}{|c|}{ Patient knows medication's major side effects } \\
\hline No & 280 & 66.4 \\
\hline Yes & 142 & 33.6 \\
\hline \multicolumn{3}{|c|}{ Patient knows instructions on how to use medication } \\
\hline No & 97 & 23.0 \\
\hline Yes & 325 & 77.0 \\
\hline \multicolumn{3}{|c|}{ Patient knows what to do in cases of missed dose } \\
\hline No & 276 & 65.4 \\
\hline Yes & 146 & 34.6 \\
\hline \multicolumn{3}{|c|}{ Patient knows medication's proper storage } \\
\hline No & 172 & 40.8 \\
\hline Yes & 250 & 59.2 \\
\hline \multicolumn{3}{|c|}{ Patient understands medication's label } \\
\hline No & 107 & 25.4 \\
\hline Yes & 315 & 74.6 \\
\hline \multicolumn{3}{|c|}{ Patient knows expected therapy outcome } \\
\hline No & 118 & 28.0 \\
\hline Yes & 315 & 72.0 \\
\hline \multicolumn{3}{|l|}{ Overall exit knowledge status } \\
\hline $\begin{array}{l}\text { Sufficient knowledge } \\
\text { ( } \geq 8 \text { positive responses) }\end{array}$ & 194 & 46.0 \\
\hline $\begin{array}{l}\text { Not sufficient knowledge } \\
\text { (<8 positive responses) }\end{array}$ & 228 & 54.0 \\
\hline
\end{tabular}

Abbreviation: HFSUH, Hiwot Fana Specialized University Hospital.

questionnaire. The questionnaire was designed in part using the WHO document of Management Science for Health and the Ethiopian Food, Medicine and Healthcare Administration and Control Authority parameters for good dispensing practices. ${ }^{13,14}$ Information included in the interview questionnaire included details about age, sex, educational levels, occupational status, marital status, ethnicity, facility setting, interaction variables with pharmacy service providers, and knowledge variables for the dispensed drugs.
The structured interview questionnaire has two parts. The first part specifically addressed sociodemographics of patients, by collecting information on age, sex, educational levels, occupational status, marital status, and ethnicity. This part of the questionnaire also inquired information of interaction variables with pharmacy service providers. The second part of the questionnaire's focus was on patient knowledge regarding dispensed drugs. To assure the data quality during the study, the structured interview questionnaire was extensively piloted (pretested on 22 ambulatory patients who took their medication from outpatient pharmacy of Jugel Hospital) before implementation. The pretest data were utilized to modify and enhance the final questionnaire. Based on their competence and experience, two pharmacy professionals were recruited and trained for the data collection. The data collectors interviewed the patients, and the patients' responses were reviewed following each interview. In addition, to ensure consistent patient understanding of the interview questionnaire, the questionnaire was translated to Amharic and Afan Oromo languages, the primary languages spoken in the study region. The local language questionnaires were retranslated back into English to verify the accuracy of the original translations. Every day after data collection, each datum was also reviewed and checked for completeness by the supervisor and the principal investigator; and the necessary feedback was given to the data collectors on the next day. Moreover, before each interview, the study participants were also well oriented about the study topic, focusing on the main objectives and advantages of answering the questions honestly.

\section{Statistical analysis}

Data were entered into an Epi-info Version 3.5.1 (CDC, Atlanta, GA, USA) and analyzed by using Statistical Package for the Social Sciences (SPSS) Version 20.0 (IBM, Armonk, NY, USA). Percent and frequency were the descriptive statistics employed to summarize sociodemographic characteristics, the extent of interaction between the pharmacists and patients, and the knowledge status of patients for the dispensed drugs. A $\chi^{2}$ test was employed to identify the potential covariates of exit knowledge for dispensed drugs at the outpatient pharmacy of HFSUH. The covariate with $P$-value less than 0.20 by bivariate analysis was retained for the subsequent multivariate analysis. Univariable and multivariable logistic regression analyses were conducted to establish associations between patient marital status, patient educational levels, perceived clarity of the pharmacist's voice, perceived politeness of the pharmacist, and 
perceived simplicity of instruction given to each patient by the pharmacist and the outcome variable (exit knowledge of dispensed drugs by the patient). In all of the analyses, significance testing was conducted using two-sided $P$-values $(P)$ and $95 \%$ confidence intervals (CIs). In all of the cases, $P$-value $<0.05$ was considered significant.

\section{Ethical consideration}

The ethical clearance and study approval was obtained from Haramaya University, College of Health and Medical Sciences, School of Pharmacy (SOP/874/02/2016). Permission to interview the study participants was obtained officially from the administrative office of the hospital. Verbal informed consent was obtained from each participant prior to the interview.

\section{Results}

In this study, 422 ambulatory patients were interviewed, and characteristics of the patients are summarized in Table 2. As shown in Table 2, the majority of the patients interviewed were female (59.2\%), were aged 19-29 years (36\%), were married (60.9\%), had finished primary (26.8\%)

Table 2 Sociodemographic and interaction characteristics of respondents at $\mathrm{HFSUH}$, Harar, June 2016

\begin{tabular}{lll}
\hline Characteristics & Frequency & $\%$ \\
\hline Sex & 250 & \\
Male & 172 & 59.2 \\
Female & & 40.8 \\
Age (years) & 28 & \\
$\leq 18$ & 152 & 6.6 \\
$19-29$ & 123 & 36.0 \\
$30-39$ & 73 & 29.1 \\
$40-49$ & 34 & 17.3 \\
$50-59$ & 12 & 8.1 \\
$\geq 60$ & & 2.8 \\
Marital status & 136 & \\
Single & 257 & 32.2 \\
Married & 17 & 60.9 \\
Divorced & 8 & 4.0 \\
Widowed & 4 & 1.9 \\
Separated & & 0.9 \\
Educational status & 70 & 16.6 \\
Illiterate & 30 & 7.1 \\
Can read and write & 113 & 26.8 \\
Primary & 116 & 27.5 \\
Secondary & 93 & 22.0 \\
Tertiary & & \\
Religion & 233 & 55.2 \\
Muslim & 130 & 30.8 \\
Orthodox & 59 & $($ Continued) \\
Protestant & & \\
\hline & &
\end{tabular}

Table 2 (Continued)

\begin{tabular}{lll}
\hline Characteristics & Frequency & $\%$ \\
\hline Occupation & 103 & \\
$\quad$ Farmer & 124 & 24.4 \\
Government employee & 58 & 29.4 \\
Merchant & 19 & 13.7 \\
Laborer & 19 & 4.5 \\
Private employee & 80 & 4.5 \\
Student & 17 & 19.0 \\
Housewife & 3 & 4.0 \\
Retirement & & 0.7 \\
Ethnicity & 237 & \\
Oromo & 34 & 56.2 \\
Harari & 99 & 8.1 \\
Amhara & 25 & 23.5 \\
Tigrie & 19 & 5.9 \\
Somali & 8 & 4.5 \\
Other* & & 1.9 \\
Residence & 266 & \\
Urban & 156 & 63.0 \\
Rural & & 37.0 \\
Pharmacy visit frequency & 70 & 16.6 \\
First time & 130 & 30.8 \\
Second time & 222 & 52.6 \\
Repeated times & & 40.5 \\
Income per month (Birr) & 151 & 59.5 \\
$\quad<724$ & 251 & \\
Z724 & &
\end{tabular}

Perceived interaction status with pharmacist rated by patient

$\begin{array}{lll}\text { Poor } & 31 & 7.3 \\ \text { Fair } & 121 & 28.7 \\ \text { Good } & 270 & 64.0\end{array}$

Primary language communicated by patient

$\begin{array}{lll}\text { Amharic } & 207 & 49.1\end{array}$

$\begin{array}{lll}\text { Afan Oromo } & 185 & 43.8\end{array}$

$\begin{array}{lll}\text { Adarigna } & 15 & 3.6\end{array}$

Somaligna $\quad 15 \quad 3.6$

Perceived clearness of pharmacist's voice and tone

$\begin{array}{lll}\text { Clear } & 352 & 83.4\end{array}$

$\begin{array}{lll}\text { Not clear } & 70 & 16.6\end{array}$

Perceived comfort of waiting area

$\begin{array}{lll}\text { Not comfortable } & 4 \mathrm{I} & 9.7\end{array}$

Fairly comfortable $\quad 60 \quad 14.2$

Comfortable 32I 76.1

Perceived politeness of service provider

Polite $355 \quad 84.1$

Fairly polite $\quad 42 \quad 10.0$

Impolite $25 \quad 5.90$

Perceived clearness of the pharmacist's instruction for patient

$\begin{array}{lll}\text { Clear } & 342 & 81.0\end{array}$

$\begin{array}{lll}\text { Fairly clear } & 43 & 10.2\end{array}$

$\begin{array}{lll}\text { Not clear } & 37 & 8.8\end{array}$

Perceived sufficiency of pharmacist's knowledge

$\begin{array}{lll}\text { Enough } & 274 & 64.9 \\ \text { Not enough } & 99 & 23.5 \\ \text { Do not know } & 49 & 11.6\end{array}$

Note: Other* stands for Argoba, Gurage and other minor ethnic groups in the area. Abbreviation: HFSUH, Hiwot Fana Specialized University Hospital. 
or secondary $(27.5 \%)$ levels of education, were Muslims (55.2\%), belonged to the Oromo ethnic group (56.2\%), and were urban dwellers (63\%). Similarly, more than half of the patients were experienced outpatient pharmacy visitors $(52.6 \%)$, and $76.1 \%$ of the patients perceived the waiting area to be comfortable. In addition, the majority of the patients interviewed perceived their interaction with the pharmacist to be positive. Specifically, $83.4 \%, 84.1 \%, 81 \%$, and $64.9 \%$ of the patients' perception was positive for voice and tone of the pharmacist, pharmacist interaction with the patient, instruction of pharmacist received by the patient, and knowledge of the pharmacist, respectively.

The knowledge status of the patients interviewed on exit from the outpatient pharmacy of HFSUH was assessed and is summarized in Table 1. The majority of the patients recalled the following information about their dispensed medication: route of administration ( $83.2 \%)$, duration of therapy (55.9\%), frequency of use $(87.7 \%)$, drug interaction (58.3\%), instruction on how to use $(77 \%)$, proper storage $(59.2 \%)$, and expected therapeutic outcome $(72 \%)$. However, less than half of the patients were able to recall the name of the medication
(46.4\%), the major side effects of the medication $(33.6 \%)$, or what to do in cases of missed doses $(34.6 \%)$. Overall, less than half $(46 \%)$ of the ambulatory patients met the defined criteria regarding knowledge of their dispensed medication at the exit interview (that is at least eight positive responses out of the twelve knowledge questions).

To determine the factors associated with the knowledge of patients for dispensed drugs, regression analyses were made. The univariable regression analyses showed positive correlations between the knowledge of patients for dispensed drugs and number of different variables (Table 3). Patients having attained primary (crude odds ratio [COR]: 2.37; 95\% CI: 1.25-4.51), secondary (COR: 2.87 ; 95\% CI: $1.51-$ 5.45), and tertiary (COR: 3.55; 95\% CI: 1.82-6.93) levels of education, who perceived the instructions received from the pharmacist as clear (COR: 4.09; 95\% CI: 1.48-11.31), who perceived the behavior of pharmacist as polite (COR: 2.26; 95\% CI: 1.28-3.96), and who perceived the voice and tone of pharmacist as clear (COR: 2.44; 95\% CI: 1.39-4.27) demonstrated a greater knowledge of their dispensed drugs at exit from the outpatient pharmacy of HFSUH. Similarly, after

Table 3 Regression analysis for factors associated with exit knowledge of patients for dispensed drugs at outpatient pharmacy of HFSUH, Harar, June 2016

\begin{tabular}{|c|c|c|c|c|}
\hline Variable & COR $(95 \% \mathrm{Cl})$ & $P$-values & AOR $(95 \% \mathrm{CI})$ & P-values \\
\hline \multicolumn{5}{|c|}{ Educational status of patient } \\
\hline Illiterate & $\mathrm{I}$ & & $\mathrm{I}$ & \\
\hline Read and write & $\mathrm{I} .15(0.45-2.95)$ & 0.77 & $\mathrm{I} .12(0.42-2.95)$ & 0.81 \\
\hline Primary & $2.37(1.25-4.5 I)$ & 0.009 & $1.97(1.01-3.84)$ & $0.04 *$ \\
\hline Secondary & $2.87(1.51-5.45)$ & 0.001 & $2.04(1.04-4.04)$ & $0.03^{*}$ \\
\hline Tertiary & $3.55(1.82-6.93)$ & $<0.001$ & $2.71(1.35-5.46)$ & $0.005^{*}$ \\
\hline \multicolumn{5}{|c|}{ Perceived clearness of instruction of pharmacist } \\
\hline Not clear & I & & I & \\
\hline Fairly clear & $4.04(1.73-9.45)$ & 0.001 & $2.25(0.90-5.63)$ & 0.08 \\
\hline Clear & $4.09(|.48-| 1.31)$ & 0.007 & $3.36(1.16-9.72)$ & $0.04 *$ \\
\hline \multicolumn{5}{|c|}{ Perceived politeness of pharmacist } \\
\hline Impolite & I & & I & \\
\hline Polite & $2.26(1.28-3.96)$ & 0.005 & $2.02(1.04-4.04)$ & $0.04 *$ \\
\hline \multicolumn{5}{|c|}{ Marital status of patient } \\
\hline Single & I & & I & \\
\hline Married & $0.44(0.28-0.67)$ & $<0.001$ & $0.53(0.33-0.84)$ & $0.007^{*}$ \\
\hline Divorced & $0.27(0.09-0.82)$ & 0.02 & $0.4 I(0 .|3-| .3 \mid)$ & 0.13 \\
\hline Widowed & $0.09(0.01-0.78)$ & 0.03 & $0.12(0.01-1.04)$ & 0.055 \\
\hline Separated & $1.97(0.20-19.50)$ & 0.56 & $2.74(0.26-28.4)$ & 0.39 \\
\hline \multicolumn{5}{|c|}{ Perceived clarity of pharmacist's voice and tone } \\
\hline Not clear & I & & I & \\
\hline Clear & $2.44(1.39-4.27)$ & 0.002 & $1.77(0.94-3.31)$ & 0.07 \\
\hline \multicolumn{5}{|c|}{ Pharmacy visit frequency } \\
\hline First time & I & & I & \\
\hline Second time & $\mathrm{I} .50(0.83-2.70)$ & 0.17 & I.37 (0.72-2.62) & 0.33 \\
\hline Repeated visit & $1.25(0.72-2.16)$ & 0.42 & I.I $4(0.62-2.09)$ & 0.66 \\
\hline
\end{tabular}

Note: Asterisk $(*)$ shows significant difference.

Abbreviations: AOR, adjusted odds ratio; $\mathrm{Cl}$, confidence interval; COR, crude odds ratio; HFSUH, Hiwot Fana Specialized University Hospital. 
adjusting for covariates, multivariable analyses revealed a statistically significant association between the levels of education of the patients and their knowledge of dispensed drugs. That is, patients with primary (adjusted odds ratio [AOR]: 1.97; 95\% CI: 1.01-3.84), secondary (AOR: 2.04; 95\% CI: 1.04-4.04), and tertiary (AOR: $2.71 ; 95 \% \mathrm{CI}: 1.35-5.46$ ) levels of education had a significantly increased knowledge of the dispensed drugs compared to illiterate patients. Furthermore, clear instruction of pharmacist (AOR: 3.36; 95\% CI: 1.16-9.72) and the polite character of pharmacist (AOR: 2.02; 95\% CI: 1.04-4.04) also positively influenced the knowledge of the patients for the dispensed drugs compared to their respective reference category. However, the knowledge of dispensed drugs was significantly decreased among married patients (AOR: 0.53 ; 95\% CI: $0.33-0.84$ ) compared to patients who were single.

\section{Discussion}

This cross-sectional study found that different patient and pharmacist factors influence the exit knowledge status of the ambulatory patients. Educational background of patients, positive patient-pharmacist interaction, and marital status of patients were the major factors that influenced the exit knowledge of the patients for dispensed drugs at outpatient pharmacy of HFSUH. Specifically, the formal educational level of patients (primary, secondary, or tertiary); clear instruction of the pharmacist; and politeness of the pharmacist were the factors associated with increased exit knowledge of the ambulatory patients for dispensed drugs, but the knowledge was also low among the married patients.

This study indicates that exit knowledge of dispensed drugs by ambulatory patients shows an increasing trend across the levels of the patients' educational background. It was 1.97 times, 2.04 times, and 2.71 times more likely in patients with primary, secondary, and tertiary levels of education, respectively, compared to illiterate patients. In agreement to this finding, different studies report that educational level of a patient is positively linked to his/her knowledge for dispensed drugs and adherence to the drug treatment regimen. ${ }^{9,15,16}$ Another study addressed the role of well-designed written information as a useful enhancement to professional consultation and advice, ${ }^{17}$ leading to possible improvement in health knowledge and recall. However, written information will clearly only benefit educated patients rather than those who are illiterate. Given that approximately $23.7 \%$ of the patients interviewed at exit from outpatient pharmacy of the HFSUH had no formal education, this raises the question as to how to improve medication understanding of such patients. To this end, some studies suggest that the use of different pictorial aids by prescribers and dispensers can improve recall and comprehension of illiterate patients and also increases adherence to their drug treatment. ${ }^{18-20}$

Clear instruction given to patient by pharmacist was also found to influence the likelihood that patients would acquire adequate knowledge of their dispensed drugs. This knowledge was 3.36 times and 2.02 times more likely in patients who perceived the pharmacist's instruction and interaction to be clear and polite, respectively, compared to patients who perceived the pharmacist's instruction and interaction as unclear and impolite. Supporting this finding, a number of different studies describe the effect of patient-centered instruction to better understand orientation for dispensed drug use..$^{10,21,22}$ Consistently, the provision of clear instructions and optimum positive interaction that can be achieved between pharmacists and their patients has been shown to emanate from the pharmacists' communication skill and use of motivational conversation. ${ }^{23,24}$ Furthermore, effective interaction between the pharmacist and other health practitioners is important to achieve characteristic changes toward patient benefit. ${ }^{25}$ Generally, practitioners collaborate with patients for their patients' health, and the success of this collaborative effort is dependent on the ability of their interaction in motivating the patient toward positive behaviors. ${ }^{26}$ Moreover, several studies demonstrate the importance of pharmacist involvement in constant patient counseling to significantly improve patient knowledge and adherence for dispensed drug(s). ${ }^{27-29}$ Therefore, it is unsurprising that these study results indicate that a pharmacist interacting with his/her patient through his/her polite and clear instruction is capable of positively influencing the exit knowledge of the patient for their dispensed drug(s).

In contrast to the educational background of the patient and the pharmacist-patient interaction factors, a negative association was found between marital status and exit knowledge of patients for their dispensed drugs. Compared to single patients, married patients were 0.53 times less likely to demonstrate adequate exit knowledge for dispensed drugs. One hypothesis is that the independent living of a single patient requires more self-responsibility and autonomy, thus a higher odds ratio in the single patients (AOR:1.0) in relation to the exit knowledge could be expected. However, in contrast to this finding, other studies have reported the role of family support or marital status in increasing adherence to dispensed medication. ${ }^{30-32}$ Indirectly, the increased adherence to treatment could result from patients' understanding of the drugs dispensed to them. A report of no effect of 
marital status on compliance to medication dispensed was also noted. ${ }^{32}$ In addition, although not statistically significant, a study done in Italy revealed that married individuals showed greater nonadherence to medication $(60 \%)$ compared to unmarried patients. ${ }^{33}$ It is possible that the high proportion of married patients participating in this study $(60.9 \%)$ introduced some bias into the study findings; however, still the direct relationship between marital status of patients and their exit knowledge status for dispensed drugs lacks clear explanation.

\section{Study limitations}

In this study, the authors tried to assess the exit knowledge of ambulatory patients for dispensed drugs, which is subjective to the information retention and recall ability of each patient. This could result into an underestimation of the knowledge measurement. However, since drug information retention ability of ambulatory patients was thought to be affected by the number of drugs dispensed to them, only those patients who received a less than or equal to three drugs from the outpatient pharmacy were assessed for the exit knowledge. Apart from the aforementioned limitation, patients who answered at least two-thirds of the knowledge questions were considered knowledgeable for the dispensed drugs, and this might have also resulted into underestimation of the knowledge status. Therefore, any interpretation of the findings in this study needs to be made in consideration of aforementioned limitations.

\section{Conclusion}

The current cross-sectional study found that the majority of the patients served at the outpatient pharmacy of HFSUH had poor understanding about the name of the dispensed drug(s), side effect(s), and what to do in case of missed dose(s). In addition, patient factors, such as educational status and marital status, and pharmacist factors, were the factors significantly associated with the exit knowledge of patients for dispensed drugs. Therefore, increasing educational coverage and standards across the community and improving communication skills training for pharmacists would likely optimize patient-pharmacist interaction, which in turn would improve exit knowledge of patients for dispensed drugs.

\section{Acknowledgments}

First and foremost, the authors thank almighty God for making this aspiration come to fruition through His grace. The authors would also like to acknowledge School of Pharmacy, Haramaya University, for reviewing and granting approval of the study. The authors thank Mr Pete Lambert for his constructive language and editorial comments. Lastly, our special thanks also go to administrative office, data collectors, patients, and workers of the HFSUH for their cooperation.

\section{Disclosure}

The authors report no conflicts of interest in this work.

\section{References}

1. Holloway K, Van Dijk L. The World Medicines Situation: Rational Use of Medicines. 3rd ed. Geneva, Switzerland: WHO; 2011:1-22.

2. WHO. Promoting rational use of medicines: core components. Geneva, Switzerland; 2002:1-6.

3. Alam K, Mishra P, Prabhu M, et al. A study on rational drug prescribing and dispensing in outpatients in a tertiary care teaching hospital of Western Nepal. Kathmandu Univ Med J. 2006;4(4):436-443.

4. Nigussie WD. Patient counselling at dispensing of medicines in health care facility outpatient pharmacies of Bahir Dar city, Northwest Ethiopia. Sci J Public Health. 2014;2(2):126-134.

5. Schnipper JL, Kirwin JL, Cotugno MC, et al. Role of pharmacist counseling in preventing adverse drug events after hospitalization. Arch Intern Med. 2006;166:565-571.

6. Beney J, Bero L, Bond CM. Expanding the roles of outpatient pharmacists: effects on health services utilisation, costs, and patient outcomes (review). Cochrane Collaboration. 2009;(2):1-52.

7. WHO. The role of education in the rational use of medicines. New Delhi, India: WHO; 2006;(45):1-88.

8. Boonstra E, Lindbaek M, Ngome E, Tshukudu K, Fugelli P. Labelling and patient knowledge of dispensed drugs as quality indicators in primary care in Botswana. Qual Saf Health Care. 2003;12:168-175.

9. Akici A, Kalaca S, Ugurlu MU, Toklu HZ, Iskender E, Oktay S. Patient knowledge about drugs prescribed at primary healthcare facilities. Pharmacoepidemiol Drug Saf. 2004;13:871-876.

10. Garjani A, Rahbar M, Ghafourian T, et al. Relationship of pharmacist interaction with patient knowledge of dispensed drugs and patient satisfaction. East Mediterr Health J. 2009;15(4):934-943.

11. Abdulah R, Barliana MI, Pradipta IS, Halimah E, Diantini A, Lestari K. Assessment of patient care indicators at community pharmacies in Bandung city, Indonesia. Southeast Asian J Trop Med Public Health. 2014; 45(5):1196-1201.

12. Angamo MT, Wabe NT, Raju NJ. Assessment of patterns of drug use by using World Health Organization's prescribing, patient care and health facility indicators in Selected Health Facilities in Southwest Ethiopia. J Appl Pharm Sci. 2011;01(7):62-66.

13. Management Science for Health. Ensuring good dispensing practices. In: MDS3 - Managing Access to Medicines and Health Technologies. Arlington, VA: Management Science for Health; 2012.

14. FMHACA US. Manual for Medicines Good Dispensing Practice. 2nd ed. Ethiopia: FMHACA; 2012:1-76.

15. Alkatheri AM, Albekairy AM. Does the patients' educational level and previous counseling affect their medication knowledge? Ann Thorac Med. 2013;8(2):105-108.

16. Ngoh LN. Health literacy: a barrier to pharmacist-patient communication and medication adherence. Pharmacy Today. 2009;15(8):45-57.

17. Coulter A, Ellins J. Effectiveness of strategies for informing, educating, and involving patients. BMJ. 2007;335:24-27.

18. Katz MG, Kripalani S, Weiss BD. Use of pictorial aids in medication instructions: a review of the literature. Am J Health Syst Pharm. 2006;63:2391-2397.

19. Clayton M, Syed F, Rashid A, Fayyaz U. Improving illiterate patients understanding and adherence to discharge medications. BMJ Qual Improv Rep. 2012;1(1):1-4. 
20. American Association of Colleges of Pharmacy, National Community Pharmacist Association. Innovative medication adherence educators challenge: summary of submissions. Joint Commission of Pharmacist Practitioners (JCPP); 2012:1-17.

21. Tullio PL, Eraker SA, Jepson C, et al. Patient medication instruction and provider interactions: effects on knowledge and attitudes. Health Educ Q. 1986;13(1):51-60.

22. Morrow DG, Weiner M, Young J, Steinley D, Deer M, Murray MD. Improving medication knowledge among older adults with heart failure: a patient-centered approach to instruction design. Gerontologist. 2005; 45(4):545-552.

23. Perri M. Communication skills for pharmacists. Am J Pharm Educ. 2006;70(1):1-3

24. Marissa C, Salvo MC, Cannon-Breland ML. Motivational interviewing for medication adherence. Pharmacy Today. 2015;21(6):81-89.

25. Geurts MME. Medication review and reconciliation with cooperation between pharmacist and general practitioner and the benefit for the patient: a systematic review. Br J Clin Pharmacol. 2012;74(1):16-33.

26. Martin LR, Williams SL, Haskard KB, DiMatteo MR. The challenge of patient adherence. Ther Clin Risk Manag. 2005;1(3):189-199.

27. Rani NV, Soundararajan P, Samyuktha CHL, Kannan G, Thennarasu P. Impact of clinical pharmacist provided education on medication knowledge and adherence of hemodialysis patients in a South Indian University Hospital. Asian J Pharm Clin Res. 2013;6(4):24-27.
28. Chisholm-Burns MA, Lee JKP, Spivey CA, et al. US pharmacists' effect as team members on patient care systematic review and meta-analyses. Med Care. 2010;48:923-933.

29. Renuga E, Ramakrishnan SR, Vanitha Rani N, Thennarasu P, Kannan G. Impact of continuous patient counseling on knowledge, attitude, and practices and medication adherence of diabetic patients attending outpatient pharmacy services. Asian J Pharm Clin Res. 2016;9:364-369.

30. Morisky DE, Ang A, Krousel-Wood M, Ward HJ. Predictive validity of a medication adherence measure in an outpatient setting. $J$ Clin Hypertens. 2008;10(5):348-354.

31. DiMatteo MR. Social support and patient adherence to medical treatment: a meta-analysis. Health Psychol. 2004;23(2):207-218.

32. Jin J, Sklar GE, Oh VMS, Li SC. Factors affecting therapeutic compliance: a review from the patient's perspective. Ther Clin Risk Manag. 2008;4(1):269-286.

33. D'inca R, Bertomoro P, Mazzocco K, Vettorato MG, Rumiat R, Sturniolo GC. Risk factors for non-adherence to medication in inflammatory bowel disease patients. Aliment Pharmacol Ther. 2007;27: $166-172$.
Patient Preference and Adherence

\section{Publish your work in this journal}

Patient Preference and Adherence is an international, peer-reviewed, open access journal that focuses on the growing importance of patient preference and adherence throughout the therapeutic continuum. Patient satisfaction, acceptability, quality of life, compliance, persistence and their role in developing new therapeutic modalities and compounds to optimize

\section{Dovepress}

clinical outcomes for existing disease states are major areas of interest for the journal. This journal has been accepted for indexing on PubMed Central. The manuscript management system is completely online and includes a very quick and fair peer-review system, which is all easy to use. Visit http://www. dovepress.com/testimonials.php to read real quotes from published authors. 